\title{
Community resilience assessment to support climate change adaptation in Cambodia and Viet Nam
}

Chris Jacobson ${ }^{a^{*}}$, Tuan Tuu ${ }^{\mathrm{b}}$, Phong Tran ${ }^{\mathrm{b}}$, Emtotim Sieng ${ }^{\mathrm{c}}$, Chanseng Nguon ${ }^{\mathrm{c}}$, Kim Nong ${ }^{\mathrm{d}}$, Patrick Nunn ${ }^{\mathrm{a}}$ and Timothy Smith ${ }^{\mathrm{a}}$

a Sustainability Research Centre, University of the Sunshine Coast, Sippy Downs, Queensland, 4558, Australia

$b$ Faculty of Hospitality and Tourism, Hue University, 22 Lam Hoang street, Hue city, Viet Nam

c Institute for Social \& Environmental Transition (ISET) - Viet Nam, No. 18, alley 1/42, Lane 1 Au Co, Tay Ho District, Hanoi, Viet Nam

d University of Battambang, State Highway, Battambang, Cambodia

* Corresponding author. Email: cjacobso@usc.edu.au

\section{ABSTRACT}

Rural communities throughout the Asia-Pacific are generally more exposed to climate-driven changes to their livelihoods than those in larger/urban communities. We developed and piloted a community resilience tool to be used to support climate change adaptation within existing development planning pathways. Our framework included 39 key questions based around outcomes related to (i) livelihoods and environment, (ii) infrastructure, (iii) community self-reliance, and (iv) climate and disaster management. In peri-urban Thuy Thanh (Vietnam), climate and disaster management were most concerning, with plan implementation funding the most limiting factor. In rural Vinh Hai, livelihood and environment outcomes were of most concern but again, plan implementation funding and information contributed to poorer outcomes. In rural Lvea Krang (Cambodia) community outcomes were most concerning, limited by ineffective collaboration, and plan implementation funding. In peri-urban Chamkar Samrong, all outcomes except climate and disaster management were of concern, with plan implementation funding and information the most limiting factors. Building resilience requires context-based consideration of desired outcomes and factors that affect them. Our assessment tool provides project managers with a comparably cheap means for monitoring the long-term effectiveness of uncoordinated aid donor projects in supporting community-based adaptation to climate change.

\section{KEYWORDS}

Adaptation, Assessment, Community resilience, Vulnerability

DOI

https://doi.org/10.30852/sb.2017.15

\section{DATES}

Received: 31 January 2017

Published (online): 9 November 2017

Published (PDF): 9 May 2018

\section{INTRODUCTION}

Climate change adaptation in Asia is particularly complex owing to interactions of geography, income, capacity and population change. The overwhelming majority of the population rely on subsistence agriculture, making them particularly vulnerable to both climate variability and change. For example, $80 \%$ of Cambodians depend on subsistence agriculture (mostly rice and fish) (Thomas et al. 2013). Forecast rice yield losses of $5 \%$ predicted by 2020 in Cambodia, combined with few opportunities for livelihood diversification, means that

\section{HIGHLIGHTS}

» Resilience assessment supports climate change adaptation using existing resources

» Factors limiting overall resilience are mostly dependent on context

» Limited resources and plan implementation commonly drove poor resilience outcomes

»Central Vietnam reported higher community resilience than Cambodia

» Links between climate change and development outcomes are often misunderstood 
communities may experience severe and recurrent food shortages and debt if adaptation planning is not effective (Nuorteva et al. 2010, Sovacool et al. 2012).

Community vulnerability to climate change can be minimized through adaptation planning that builds on inherent community-based sources of resilience (Adger et al. 2011). Understanding such resilience is especially important in remoter areas where communities are largely self-reliant yet may or may not have developed high degrees of adaptability to climate-driven change (Nunn et al. 2014); an additional consideration is a degree to which such communities retain their levels of traditional coping in the face of encroaching globalization. Vulnerability comprises a community's exposure to risk and their sensitivity to impacts arising from risks (Adger et al. 2011). Community resilience is broader than vulnerability, including consideration of a community's assets and the dynamics by which they are able to and are limited in mobilizing those assets to address risk. Thus, it pays greater attention to governance and social dynamics that affect a community's development trajectory (Magis 2010). Understanding each community's assets and how they can be mobilised are critical in addressing the climate change-development nexus in comparatively poor rural communities (Friend and Moench 2013, Adger et al. 2011, Adger et al. 2013) yet this understanding is limited in the Asia-Pacific region and merits further investigation (Friend et al. 2014, Nuorteva et al. 2010). Some communities and practitioners (such as those we work with) feel that some current tools for assessing vulnerability (including measuring resilience) to climate change are narrow in focus and as such, are not easily integrated into multi-sectoral development planning.

Community resilience assessment has recently emerged as an area of focus in disaster management, promulgating tool development contextualized to the needs of different programs and the aims of specific projects (see Sharifi 2016, Sharifi and Yamagata 2016 and Ross and Berkes 2014). Many of these tools are broad in nature and detailed in anticipated analysis, sometimes failing to consider how climate change and development are inter-woven, instead focussing on disaster management at the expense of considering how communities actually change and adapt (Loring et al. 2016). Further, they are often very complex and detailed, and not easily applied without expert assistance to guide local scale adaptation. Improving tools for rapid measuring and strengthening the resilience of rural communities to climate change has the potential to (i) identify the existing status of resources and processes that could be mobilised to support adaptation to climate change and enhance community resilience, and (ii) inform national and sub-national planning by identifying communities most in need of interventions to enable effective and sustained adaptation. This project developed and piloted a rapid community resilience assessment tool addressing these knowledge gaps and identified opportunities to use community resilience assessments to enhance adaptation planning.

\section{METHODOLOGY}

Our methodology included three steps: (i) assessment framework development and revision based on expert feedback ( 2 months); (ii) assessment trialling in four communes (two in Vietnam and two in Cambodia) over a period of 3 months in each commune; and (iii) adaptation policy dialogues (one day each, one in Vietnam and two in Cambodia). In conjunction with United Nations Food and Agriculture Organisation (UN FAO), we also collected some household migration and food security data for Cambodia. For tool piloting purposes, communes (typically a cluster of 3-5 villages) for which climate vulnerability data and relationships existed were selected, including ones in both peri-urban and rural situations.

Participating Vietnamese communes included Vinh Hai (rural) and Thuy Thanh (peri-urban) in Tha Thien Hue province, Central Vietnam. In these communes, urban growth has encroached in rural areas while traditional agricultural livelihoods face increased impacts from more frequent typhoon and flood events as well as groundwater salinization. Thuy Thanh has 9,717 people and Vinh Hai has 13,019 people.

Cambodian communes included Chamkar Samrong near Battambang city (peri-urban) and Lvea Krang, a rural commune in Siem Reap Province, both in Northwest Cambodia. From unpublished remotely-sensed data, it is clear that over the past 16 months these areas have experienced increasing dryness and a concomitant decrease in the number of abnormally wet months. In combination, this affects food security with consequently high rates of out-migration to the capital (Phnom Penh) and to Thailand in search of work (Kingdom of Cambodia 2014). These two communes are home to populations of approximately 17,927 and 2,963 (respectively).

\subsection{Assessment Framework Development}

Starting in 2014, we reviewed ten community resilience assessment frameworks and indicators (excluding disaster resilience on the basis that it addresses climate crises rather than slow onset change) to develop a common indicator set. We then aligned indicators against a framework based on context, management inputs, planning, plan implementation and outcomes 
(including livelihoods, infrastructure, community and climate and disaster management). This assessment structure is endorsed by the International Union for the Conservation of Nature (IUCN) to meet commitments to the Convention on Biological Diversity (Leverington et al. 2010). We developed a four-point qualitative scoring system for each of 39 questions with example high and low scores. Lastly, we revised our framework on the basis of expert feedback workshops with academics, climate change experts and NGOs, and policymakers for example, adjustment to wording and indicators. Full details of the framework can be found in Jacobson and Nguon (2016) and Tran et al. (2016). Examples of questions and scores are provided in Table 1.

This framework structure provides a rapid and

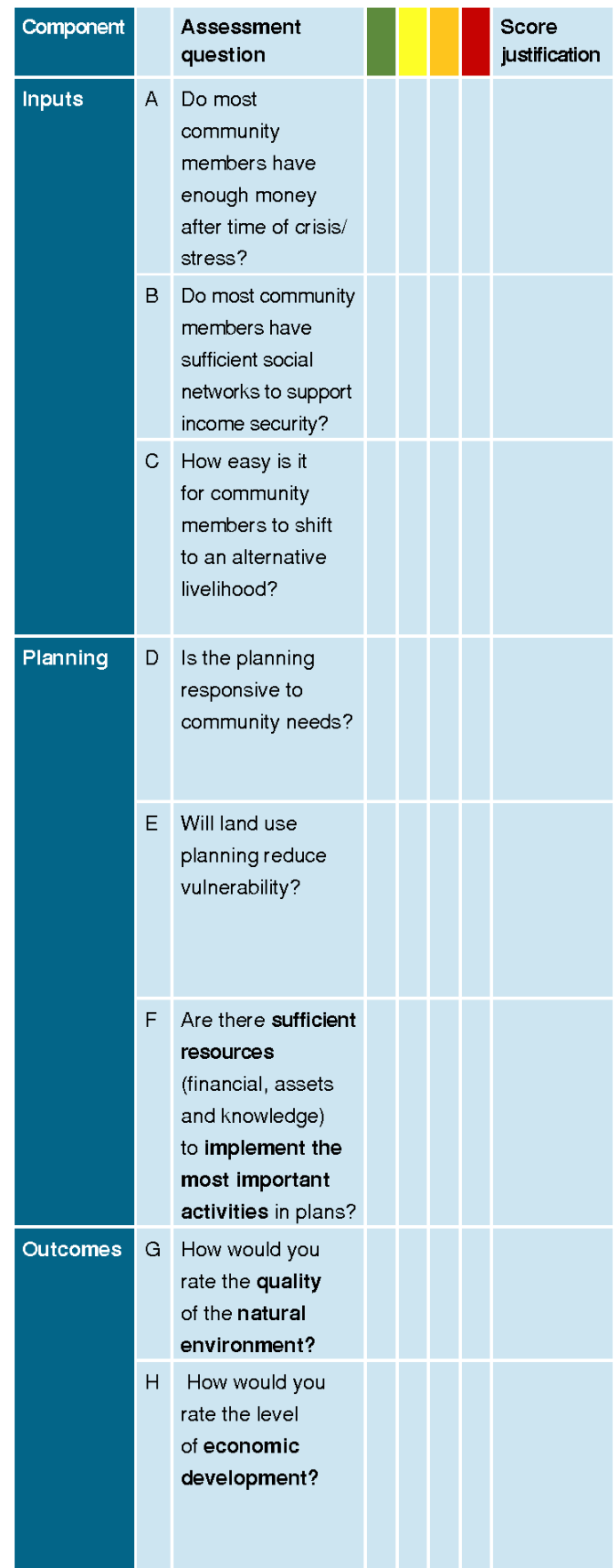

cost-effective assessment process. Qualitative assessments have been routinely criticised in monitoring and evaluation, irrespective of their ability to verify information needed for decision-making and a structured approach to planning in the absence of quantitative data (Hockings et al. 2009, Jacobson et al. in press). Where it does exist, quantitative information was incorporated into the assessment.

\subsection{Assessment Process}

The assessment was conducted as a workshop or focus group discussions with Commune Council, Village leaders and community groups in each of the four communes. In Cambodia, we also conducted a needs assessment and prioritization comparison. This included a needs prioritization ranking, a ranking

\begin{tabular}{|c|c|c|}
\hline High score & Low score & $\begin{array}{l}\text { based on access during climate-related } \\
\text { hazards, and provided a valuable basis }\end{array}$ \\
\hline $\begin{array}{l}\text { Most people have } \\
\text { strategies in place to } \\
\text { maintain livelihoods } \\
\text { during crises (e.g. } \\
\text { setting money or food } \\
\text { aside) }\end{array}$ & $\begin{array}{l}\text { No-one has enough } \\
\text { strategies in place } \\
\text { to cope during } \\
\text { crises }\end{array}$ & $\begin{array}{l}\text { from which to discuss the appropriate- } \\
\text { ness of existing resources for addressing } \\
\text { different development outcomes under } \\
\text { climate change (Jacobson and Nguon }\end{array}$ \\
\hline $\begin{array}{l}\text { Most people have } \\
\text { sufficient networks } \\
\text { within the district to } \\
\text { increase household } \\
\text { income }\end{array}$ & $\begin{array}{l}\text { Household income } \\
\text { is decreasing and } \\
\text { debt is growing for } \\
\text { most families }\end{array}$ & $\begin{array}{l}\text { drivers and consequences) and food } \\
\text { security was conducted in conjunction } \\
\text { with UN FAO, and in one commune, }\end{array}$ \\
\hline $\begin{array}{l}\text { Community } \\
\text { members can easily } \\
\text { find alternative } \\
\text { jobs or business } \\
\text { opportunities in the } \\
\text { area }\end{array}$ & $\begin{array}{l}\text { It is difficult to find } \\
\text { alternative income } \\
\text { sources and most } \\
\text { parents and or } \\
\text { families must } \\
\text { migrate for work }\end{array}$ & $\begin{array}{l}\text { Needs Assessment was undertaken as } \\
\text { part of the UN FAO project. In all cases, } \\
\text { data (either previous existing studies or } \\
\text { that which we had collected) were then }\end{array}$ \\
\hline $\begin{array}{l}\text { Commune and or } \\
\text { provincial plans address } \\
\text { these issue and it } \\
\text { reflects the top priorities } \\
\text { of the commune }\end{array}$ & $\begin{array}{l}\text { Commune and or } \\
\text { provincial plans do } \\
\text { not address these } \\
\text { issues }\end{array}$ & $\begin{array}{l}\text { summarized against community resil- } \\
\text { ience assessment questions to use as } \\
\text { prompts for discussion and assessment } \\
\text { in workshops. }\end{array}$ \\
\hline
\end{tabular}

Land use plans do reduce vulner ability from flooding, storms etc.

We have all the resources we need for top priority activities that wil build sustainable livelihoods

The environment is high quality and it seems to be staying that way

Economic development is growing, as evidenced by jobs, housing quality and services available

\section{Land use}

plans increase vulnerability for many groups, not only the poorest or most marginalised We have no resources to support sustainable livelihoods

The environment is medium to low quality and things are getting worse Economic development is bad, evidenced by fewer jobs, less food, more debt and more migration

\subsection{Adaptation Dialogue Process}

The adaptation dialogue process (Jacobson et al. in press) enabled us to share and verify results and to identify innovative opportunities for adaptation utilizing existing resources. It included representatives from relevant provincial departments, NGOs, research organizations and aid organizations. The format followed: (i) an overview of activities and a discussion of climate impacts; (ii) an overview of key results; (iii) a presentation of the assessment

FIGURE 1. Example indicators for livelihoods and environment, and scoring guide 
scores related to each outcome theme, with comments on score justification and issues by commune representatives attending meetings; and (iv) a discussion on how these issues might be addressed with prompting questions (including related provincial/NGO/University projects addressing issues identified, what would need to occur to enhance a particular score, whether existing planned activities are likely to improve scores, what can and cannot easily be changed about drivers of the issues). At the end of the process, we asked participants to summarize the most pertinent issues, to identify adaptation actions that could address them, and to determine who should be responsible for these.

\section{RESULTS}

\subsection{Viet Nam}

Thuy Thanh Commune results (Figure 2) indicate that responses to climate crises and slow-onset changes (e.g., sea-level rise) were perceived as the biggest problem for community resilience, one that was exacerbated by inadequate planning and a paucity of implementation funds. Some adaptation options identified included:

1. Improving understanding of climate change, including understanding the reasons for both insufficient stakeholder engagement in planning and perceived low levels of commune resilience and disaster preparedness. This would address poor planning scope scores for the climate and disaster management theme; and

2. Working more closely with vulnerable groups (e.g. elderly and poor) to understand and develop adaptive livelihood options. Participants felt that this would improve livelihood outcomes.

In Vinh Hai Commune, results (Figure 3) indicate that management of livelihood economic opportunities can be inferred (due to grading) as the biggest problem for community resilience, while funds to implement plans and inputs (including access to resources during times of crisis, social networks in crisis and the ability to change from one livelihood to another) were the most significant factors contributing to this. Based on scoring, this rural commune appeared better prepared for shortterm climate impacts than the Thuy Thanh Commune, although long-term strategies to address livelihood alternatives are also needed. Some adaptation options identified included:

3. Improving understanding of vulnerable groups (e.g. very poor people, elderly), including developing more sustainable livelihoods, microfinance opportunities, and the level of support available to these groups during disasters. These groups were considered most affected by poor livelihood and environment outcomes scores;

4. Identifying and investing in livelihood diversification to sustain market-driven food production in the face of adverse climate events, to address poor livelihood and environment inputs and information score; and

5. Improving disaster preparedness, including the ability to survive for more than ten days without normal services or access (given the time it takes to receive support), i.e. the yellow climate and disaster management inputs and information score.

\subsection{Cambodia}

In comparison to the two communes in Vietnam,

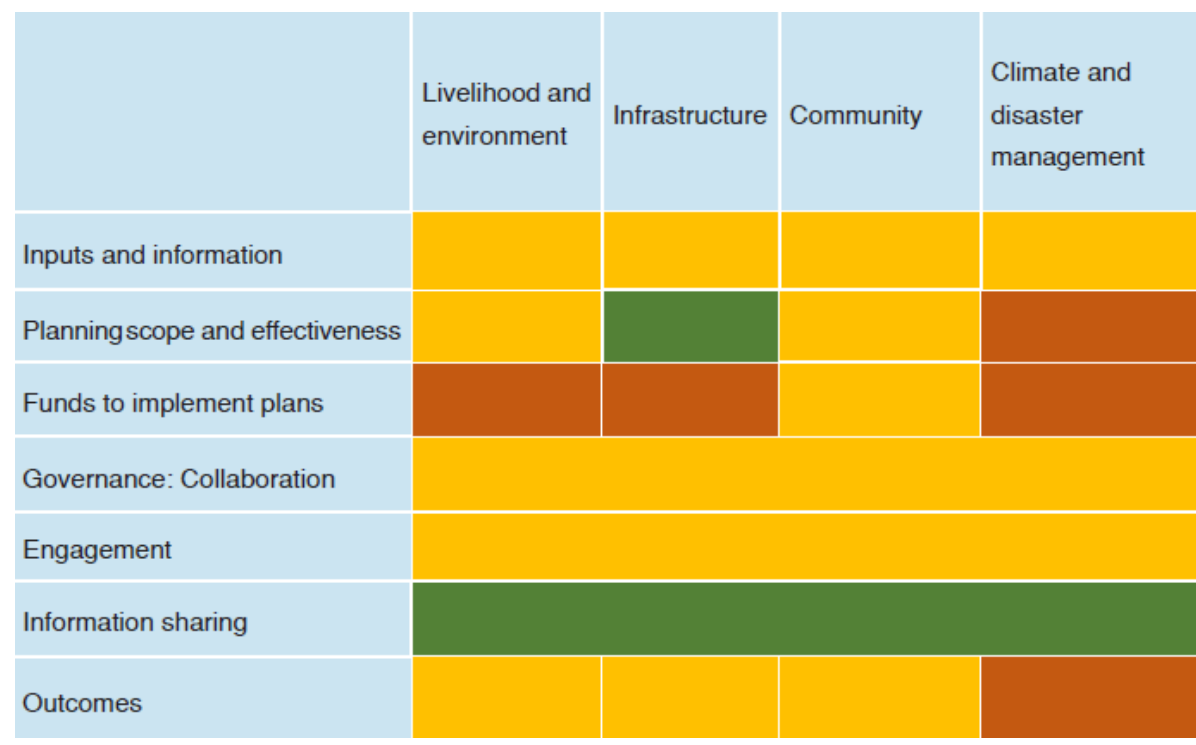

FIGURE 2. Thuy Thanh Commune resilience assessment summary. Green shading represents an element considered effectively addressed, yellow is mostly effectively addressed, whereas orange is poorly addressed. 


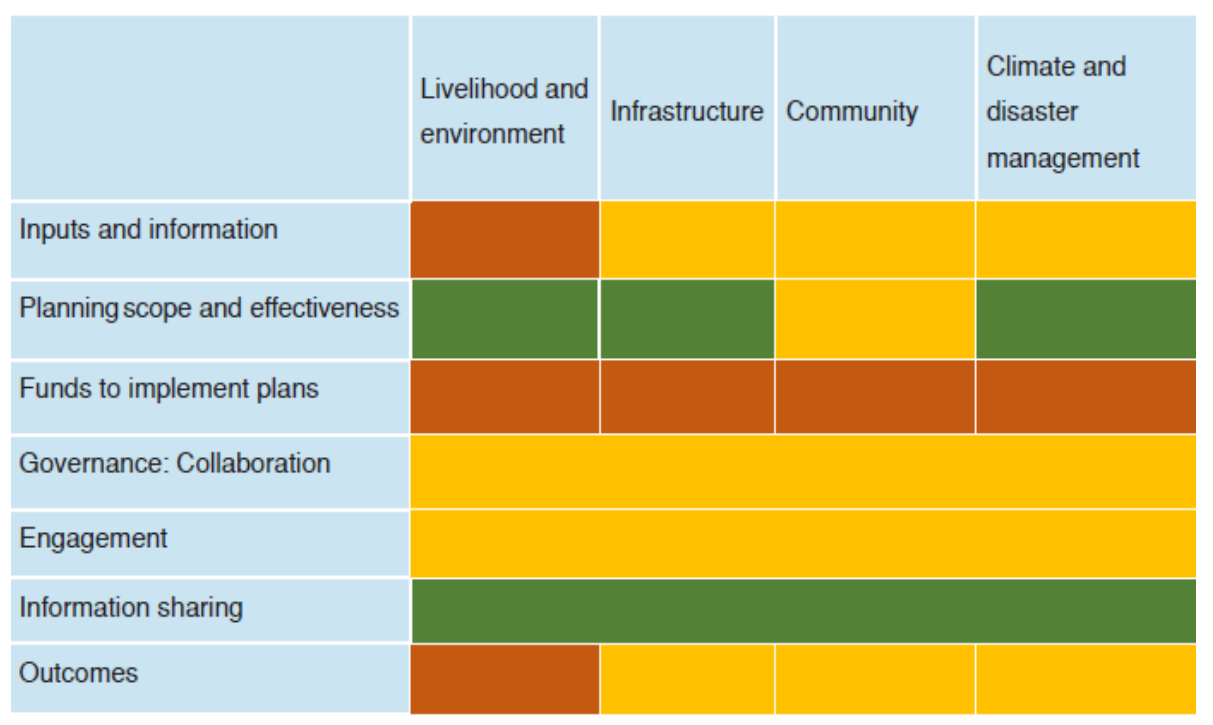

FIGURE 3. Vinh Hai Commune resilience assessment summary. Green shading represents an element considered effectively addressed, yellow is mostly effectively addressed, whereas orange is poorly addressed. community resilience in the two commune in Cambodia was rated lower, largely because of issues with inputs, information, and resources for planning, and plan implementation. In both communes studied, management of climate crises and slower-onset changes (e.g. sea-level rise) were perceived as fundamentally challenging community resilience, compounded by a range of associated factors, such as funding to implement plans, information access and in some cases, planning scope (i.e. responsiveness to commune needs).

In Lvea Krang Commune, common cross-cutting factors including a lack of information for planning, community networks for coping with crises and reconfiguring livelihoods and addressing the needs of the most vulnerable people were issues, as was the quality of collaboration between community, government, and NGOs (Figure 4). Adaptation options beyond those being addressed by the UN FAO project (focusing on climate-smart agriculture, alternative livelihoods, and watershed management) included:

Study club (focused on school curriculum) for children from migrant households, given that they often have to work in fields to help feed their family due to labour shortages incurred because of climate-re- lated food insecurity, and miss school as a result. This addresses some aspects of the poor community scores;

Improved water for drinking, sanitation and hygiene purposes, particularly in schools, as a result of climate-induced water shortages. This addresses some aspects of the poor community scores; and

Agricultural community (co-operative) for sharing information about market prices, coordinating planting to ensure markets are not saturated, coordinating use of irrigation among villages and commune, and enabling of access to climate-resilient rice seed varieties This addresses some aspects of the poor livelihood and environment scores.

Peri-urban Chamkar Samrong commune results (Figure 5) demonstrate that the commune faces a dual-development trajectory, with landholders closer to the city able to sell their land and invest in agricultural land with better water supply outside of the commune, and those living farther from the city who were unable to do so and whose land and livelihoods were thus more heavily impacted by increased frequency and severity of drought and foods, with few perceived livelihood alternatives. Our workshop participants suggested that in the last year alone, around half of agricultural lands (30\% of
FIGURE 4. Lvea Krang Commune resilience assessment summary. Green shading represents an element considered effectively addressed, yellow is mostly effectively addressed, whereas orange is poorly addressed.

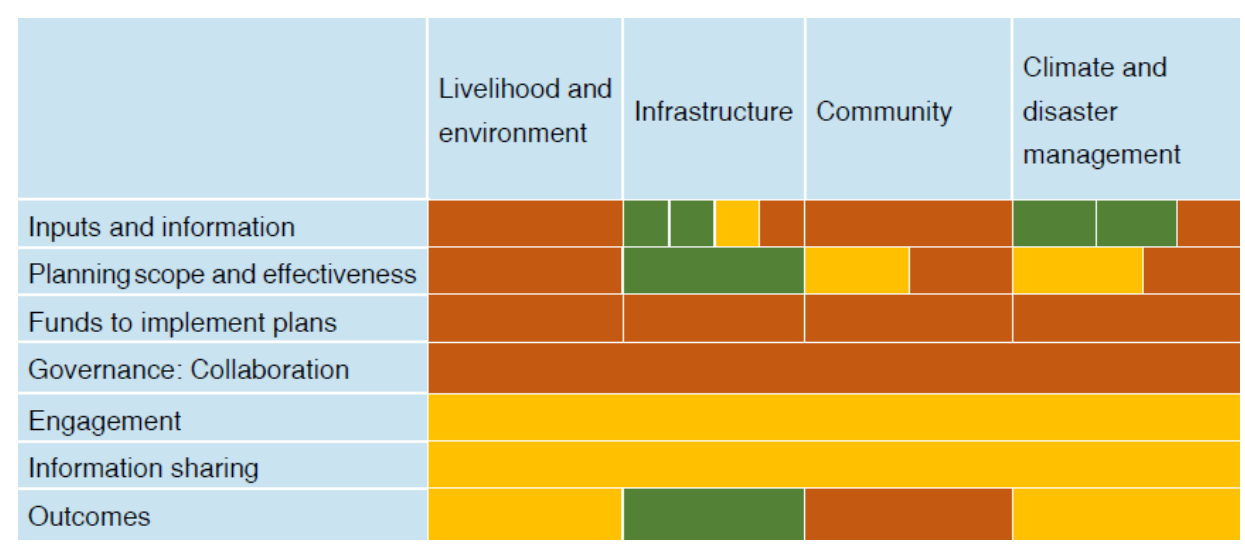




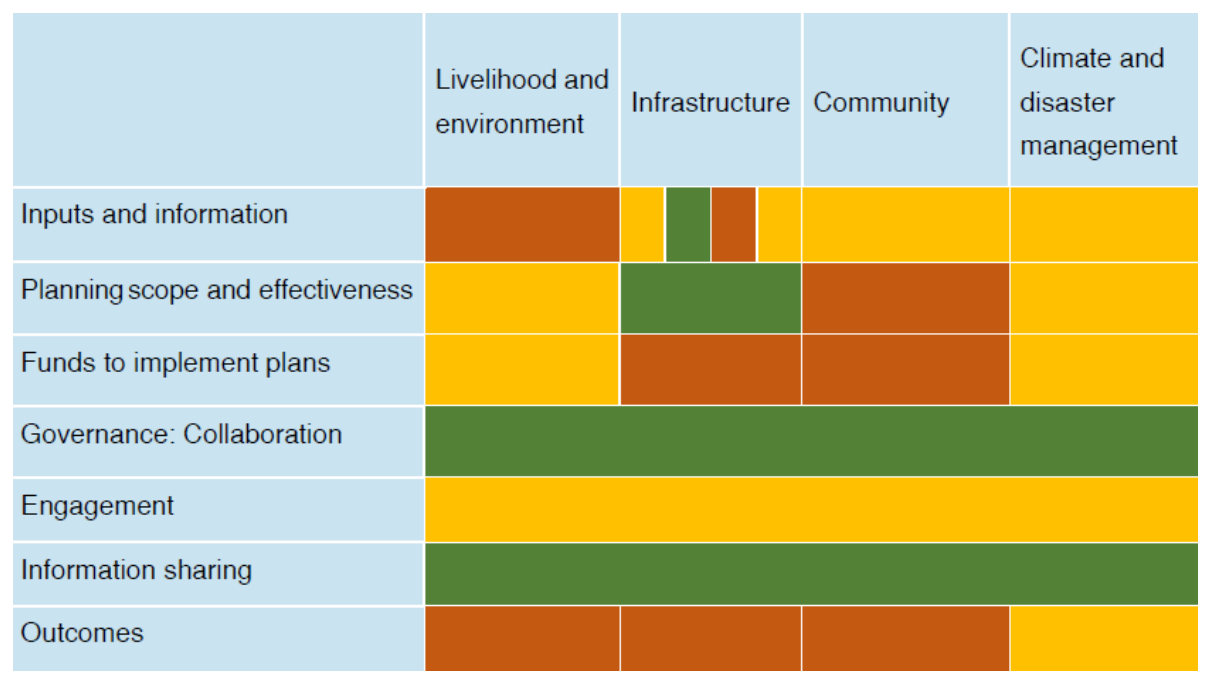

FIGURE 5. Chamkar Samrong Commune resilience assessment summary. Green shading represents an element considered effectively addressed, yellow is mostly effectively addressed, whereas orange is poorly addressed.

land area in village 1 and 2 within the commune) had been seized as collateral against microfinance loans, due to a drought that affected productivity and farmers' ability to repay loans. Collaboration and information sharing were less problematic here than for Lvea Krang, likely due to proximity to the city of Battambang that gave community members some potential cushioning from economic impacts of climate adversity through the provision of wage employment. Some adaptation options identified included:

6. Study club (as above);

7. Community gardens on school or NGO land, so that community members can learn about and grow alternative climate-resilient crops to increase food security and, with donor assistance, develop alternative livelihoods through microenterprises (e.g. herbal tea, compost development). This addresses some aspects of the poor livelihood and environment scores;

8. Climate-smart agriculture training (improve soil management and rice cropping practices to promote soil moisture retention and improve soil humus and fertility). This addresses some aspects of the poor livelihood and environment scores; and

9. Promote water and food storage for times of crisis, through commune and Department of Rural Development providing access to water storage containers and/or communal water tanks, and information about food storage in advance of floods and or drought. This addresses some aspects of the poor community scores.

\section{DISCUSSION}

The commonalities across all four communes are a lack of funds to implement plans and the general respon- siveness of infrastructure planning. We did not identify any apparent patterns in results between peri-urban and rural communes. A larger sample size may indicate differences but our results suggest that every commune appears to face a mixed bag of issues, none exactly duplicating another, that affect its resilience. Our work has demonstrated that a policy dialogue approach is critical to identifying transformative approaches to adaptation (see Thomsen et al. 2012) that address urgent issues around community viability and contribute to long-term solutions for sustaining livelihoods. This supports the suggestion that successful climate change adaptation in Asia requires attention to be shifted from plan writing to the creation of spaces for informed dialogue (Friend et al., 2014).

In general, factors contributing to livelihood and community self-reliance were scored lowest. These include issues such as the ability to ensure income security in times of climate-related crises and to diversify livelihoods post-crisis, the responsiveness of planning to community needs and to reducing vulnerability, and building community networks and engagement during climate shock and stress events. Our tool has identified factors contributing most and least to resilience outcomes. Understanding how to build resilience is considered an emerging research agenda in integrated and advanced interpretations of community and disaster resilience (Davidson et al. 2016) but could include consideration of switching resources (time, planning and other) from areas scored positively to areas scored less positively.

Communities may not necessarily have conveyed or comprehended the inter-relatedness of climate issues in the scores associated with climate and disaster management components of the assessment tool. This is the 
reason we included climate and disaster management as a development outcome, as well as incorporating elements related to climate impacts into other indicators (e.g. avoiding increased vulnerabilities as part of infrastructural development planning). The survey on climate-related household migration and social consequences undertaken in Cambodian case studies indicates likely climate-related household migration rates of $21-31 \%$, resulting in labour shortages, issues for youth, instances of lower female safety, and in as many as half the cases, lower food security (Jacobson and Nguon 2016). These issues highlight the interconnected nature of climate change-related impacts. Lastly, a lack of espoused knowledge about the pathways through which climate change can impact all development could mean communities focus on short-term solutions rather than longer-term ones that ensure adaptation pathways remain open. Adaptation activities raised during our policy dialogue included a combination of both of these, for example, study club (a short-term solution), and climate-resilience agriculture (a long-term one).

Our results also highlight the need for greater attention to issues of climate change adaptation for marginalized groups, such as female-headed households, children and elders from migrant households, and poorer families. Little if any attention has been paid to these groups within resilience assessments, especially from the perspective of empowering them to engage in adaptation processes (Reed et al. 2014). A finer dissection of vulnerable group categories may lead to improved outcomes of development and climate change adaptation. While gendered perspectives on development are not new, gender/marginalization theory and its consideration in climate adaptation for agricultural development are comparatively under-developed (Carr and Thompson 2014). Reviews of community resilience assessment, e.g., Sharifi and Yamagata (2016) and Ross and Berkes (2014) do not include marginalization as specific components or indicators of resilience, although they do refer to 'equity' without contextualizing it. Where assessments do consider marginalized groups, they generally consider binary categorizations of marginalization; for example for women (as opposed to men), or for indigenous (as opposed to non-indigenous). They do not consider that members of one grouping may have less in common than they do with others in the opposing binary, i.e. richer women may have more in common with richer men in terms of their capacity to adapt than with poorer women. In our assessment, we asked specifically about whether planning reduced vulnerability and about the needs of the most vulnerable groups. The detailed discussion of these questions and subsequent poor scores lead us to conclude that understanding how best to address the needs of marginalized groups in resilience and vulnerability assessments requires greater attention.

\section{CONCLUSION}

This project has (1) contributed a rapid assessment tool for community resilience to climate change, and (2) demonstrated that assessments of the resilience of rural communities can help to identify the current status of resources and processes that can be mobilized to support adaptation to climate change. Our tool was sufficiently simple to be utilized as part of annual Commune Investment Plans in Cambodia and Vietnam. If implemented at a regional scale covering multiple communities (i.e., if its application was scaled out), results could be used to inform subnational planning by identifying communities that are most in need of interventions and by prioritizing adaptation efforts of different types. It could also be used as a systematic basis for targeting climate-related aid. Where resources exist, quantitative proxy indicators could be developed for framework questions. This would enable us to test the rigour of assessment scale in comparisons. The sensitivity of the tool to detect changes in resilience on the basis of adaptation activities must also be examined.

Our results highlight that building resilience requires context-based consideration of desired development outcomes and factors affecting the status of them. The third contribution of our work is to demonstrate how these can be captured in both assessment design and extension dialogue processes. A benefit of our assessment and policy dialogue process is that it could be used as a rapid approach to monitoring the effectiveness of aid projects designed to support community-based adaptation to climate change, e.g. as a companion to mid-term review; there are often many projects running simultaneously in any community, but a lack of coordination across projects sometimes exists. In this way, as illustrated by our policy dialogue workshops, community members are better able to express their needs and get the attention of their provincial, aid and NGO partners. Long-term use could also indicate whether adaptation path dependency is becoming an issue.

\section{ACKNOWLEDGEMENT}

We offer our sincerest thanks to our collaboration with UN FAO Life and Nature team (Dr Stacy Crevello, Chantan Chea, and Mok Kona) in Cambodia. We thank all government, NGO, University, and community participants from the communes and provinces involved. We would also like to thank our research assistants Tran Tuan Anh, Renee Currenti, Ratha Rein and Chou Phanith, and cross-fertilization of ideas with University of the 
South Pacific staff. The team leader also acknowledges mentoring support from Terry Trethowan and Dr Iean Russel.

\section{REFERENCES}

Adger, WN, Barnett, J, Brown, K, Marshall, N and O'Brien, K, 2013, Cultural dimensions of climate change impacts and adaptation. Nature Climate Change 3: $112-117$.

Adger, WN, Brown, K, Nelson, DR, Berkes, F, Eakin H, Folke, C, Galvin K, Gunderson L, Goulden M, O'Brien, K, Ruitenbeekm J and Tompkins EL, 2011, Resilience implications of policy responses to climate change. WIRES Climate Change 2(5): 757-766.

Berkes, F, and Ross, H, 2013, Community resilience: towards an integrated approach. Society and Natural Resources 26: 5-20.

Carr, ER, and Thompson, MC, 2014, Gender and climate change adaptation in agrarian settings: current thinking, new directions, and research frontiers. Geography Compass 8(3): 182-197.

Davidson JL, Jacobson, C, Lyth, A, Baldwin, C, Dedekorkut-Howes, A, Ellison, JC, Holbrook, NJ, Howes, MJ, Serrao-Neumann, S, Singh-Peterson, L and Smith, $\mathrm{TF}, 2016$, Interrogating resilience: towards a typology to improve its operationalization. Ecology and Society 21(2)

Friend, R, and Moench, M, 2013, What are the purpose of urban climate resilience? An implication for addressing poverty and vulnerability. Urban Climate 6: 98-113.

Friend, R, Jarvie, J, Reed, SO, Sutarto, R, Thinphanga, P and Toan VC, 2014, Mainstreaming urban climate resilience into policy and planning: reflections from Asia. Urban Climate 7: 6-19

Hockings, M, Stolton, S, Dudley, N, and James, R, 2009, Data credibility - what are the "right" data for evaluating management effectiveness of protected areas? New Directions for Evaluation 122: 53-63.

Jacobson, C, Crevello, S, Nguong, C, and Chea, C, in press, Resilience, and vulnerability assessment as the basis for adaptation dialogue: a Cambodian example. In: Serrao-Neumann, S, Coudrain, A, and Coulter, L. (ed.s) Developing and communicating climate change information for decision-making. Springer.

Jacobson, C, and Ngoun, C, 2016, Community resilience assessment and climate change adaptation planning, a guidebook. The University of the Sunshine Coast, the University of Battambang (in English and Khmer). ISBN 10: 1-925476-04-9, ISBN-13: 978-1925476-04-0. 96pages.

Kingdom of Cambodia, 2014, Migration in Cambodia:
Report of the Cambodian rural-urban migration project. Ministry of Planning, Phnom Penh.

Leverington, F, Lemos Costa, K, Pavese, H, Lisle, A and Hockings, M, 2010, A global analysis of protected area management effectiveness. Environmental Management 46:685-698

Loring PA, Gerlach SC and Penn HJ, 2016, "community work" in a climate of adaptation: responding to change in rural Alaska. Human Ecology 44(1): 119-128.

Magis, K, 2010, Community resilience: an indicator of social sustainability. Society and Natural Resources 23(5): 401-416.

Nunn, PD, Aalbersberg, W, Lata, S and Gwilliam, M, 2014, Beyond the core: community governance for climate change adaptation in peripheral parts of Pacific Island Countries. Regional Environmental Change 14(1) 221-235.

Nuorteva, P, Keskinen, M and Varis, O., 2010, Water, livelihoods and climate change adaptation in the Tonle Sap area, Cambodia: learning from the past to understand the future. Journal of Water and Climate Change 1(1): 87-101.

Reed, MG, Scott, A, Natcher, D and Johnston, M, 2014, Linking gender, climate change, adaptive capacity and forest-based communities in Canada. Canadian Journal of Forest Research 44(9)995-1004.

Ross, H and Berkes F, 2014, Research approaches for understanding, enhancing and monitoring community resilience. Society and Natural Resources 27: 787-804.

Sharifi A, 2016, A critical review of selected tools for assessing community resilience. Ecological Indicators 69: 629-647.

Sharifi A and Yamagata Y, 2016, On the suitability of assessment tools for guiding communities towards disaster resilience. International Journal of Disaster Risk Reduction 18: 115-124.

Sovacool, BK, D'Agostino, AL, Meenawat, H, and Rawlani, A, 2012, Expert views of climate change adaptation in the least developed Asia. Journal of Environmental Management 97: 78-88.

Thomas TS, Ponlok T, Bansok R, Lopez T, Chiang C, Phirun N and Chhun C, 2013, Cambodia agriculture: adaptation to climate change impact. International Food Policy Research Institute.

Thomsen DC, Smith TF, and Keys N, 2012, Adaptation or manipulation? Unpacking climate change response strategies. Ecology and Society 17(3): 20

Tran T, Tran P, Anh T and Jacobson C, 2016, Community resilience assessment and climate change adaptation planning, a guidebook. The University of the Sunshine Coast, Hue University of Economics (in English and Vietnamese). 